\title{
Hygrothermal behaviour of straw bale walls: experimental tests and numerical analyses
}

\author{
Alessandra Mesa* and Alberto Arenghi \\ Department of Civil, Environmental, Architectural Engineering and Mathematics, University of Brescia, Brescia, Italy
}

Received: 8 January 2019 / Accepted: 5 September 2019

\begin{abstract}
Straw is an organic material with hygroscopical properties. The high capacity it has of storing moisture from the surroundings can furthermore influence the performance and lead to the possible degradation of the material thereof. The aim of this study was to assess the conductance C-value of a complex material such as straw. A climatic chamber was used to study a sample, which reproduces a traditional plastered straw bale wall. Tests were conducted under different boundary conditions, setting constant values for temperatures and relative humidity. The revision of the assessment's results allowed the calculation of conductance and conductivity values under different conditions. A numerical model was then designed starting from the laboratory data, which was used to characterize material properties. The match between software simulations and laboratory analyses will be a starting point for further tests. Determining the straw conductance C-value is a difficult task to achieve, due to the complexity and the unique properties of the material. In spite of all this, laboratory tests have shown encouraging results, which reflect the great potential of straw as a building material.
\end{abstract}

Keywords: straw bales / experimental studies / hygrothermal performance / thermal transmittance / natural building material

\section{Introduction}

\subsection{Background}

Straw is a waste product of the agricultural sector: it is a biodegradable by-product of cereal cultivation, which appears in abundance all over the world and does not have much economic value. It is a good material for sustainable architecture, both in terms of economic and environmental impact, due to its low emissions during production and the life cycle of buildings.

The properties of straw applied in the building sector have been known since the nineteenth century. The early market grew in Canada, which is still one of the major countries investing in it. Concerning Europe, the use of straw as a building material still raises many doubts in terms of stability and building performance. Nowadays, straw bale constructions are, therefore, uncommon, but they represent a growing market that arouses much interest in the buyer and builder.

\subsection{Objective}

Many studies have been conducted to investigate straw bale properties in building construction, further described

\footnotetext{
* e-mail: alessandra.mesa@unibs.it
}

in Sections 1.3 and 1.4, but more researches are still required to better define the behaviour thereof. Straw is a biodegradable material, so, under certain conditions of temperature and humidity, it can be affected by decay. Concerning this topic, literature provides general design suggestions, learned through experience, to avoid moisture damage, but very little has been said about the hygrothermal behaviour of straw bale walls, connected with the possibility of predicting it during the designing phase [1].

Actually the conductivity value $\lambda$ has a fundamental role within the thermal designing process of a stratigraphy. While dealing with an organic material, the assessment of this parameter is quite complex since it may be affected by several factors. The aim of the present research is therefore the characterization of straw hygrothermal properties. The paper describes six laboratory tests, which have been conducted using a climatic chamber under a semistationary regime, in order to monitor the performance of straw. Different values of the conductance $C$ were worked out for different boundary conditions (temperatures, relative humidity, tests duration). Laboratory results have been used as a necessary starting point to reproduce the specimen with a numerical analyses using WUFI. Even if this software performs dynamic calculations, the boundary conditions have been imposed to be as similar as possible to the laboratory set. The conducted 
simulations have been fit the laboratory tests and have allowed finding a satisfying correlation between the real sample and the numerical model.

\subsection{Physical aspects of straw bale buildings}

The increasing interest in the construction of houses with straw bale has led to the development of regulations and studies on the matter. In order to consider straw as a building material it has to fulfil the needed requirements for the purpose. Since we are dealing with an organic material, straw properties can be influenced by many variables such as the density of bales, fibre orientation, moisture content and type of straw in use [2-4]. Several studies have been conducted to define the thermal properties of straw in different configurations, changing parameters that may affect its behaviour. The main considered parameters are density, initial moisture content, fibre's orientation, sample's dimensions [1-11]. Despite straw has not shown thermal properties as good as traditional insulating materials, the measured $\lambda$-value combined with the thick layer of straw, usually used for this kind of walls, lead to a good overall insulating performance. Moreover, several authors have been studied to define acoustic insulation properties of straw. This theme turned out to be a complex task to achieve and tests have led to different conclusions. Some authors define straw as a good acoustic insulator $[2,3]$, but the majority of them agrees on its poor performance, mainly due to the lightness of the material, compared to traditional walls [12-14].

While several authors investigated the insulating properties of straw, the same cannot be said for its performance in terms of structural load and fire resistance. The organic nature of straw has been, a source of doubt concerning building safety and stability. Apart from few cases in which the whole structure of buildings was made by straw, using the so-called Nebraska style, in common houses straw usually does not play any structural role, which is instead carried out by a timber frame. Despite this, several studies conducted on plastered straw bales have underlined good structural properties of straw, which leaves the possibility of using this material without the support of any additional structure open $[3,4,15]$.

Moreover, with regards to fire resistance, straw has shown good properties, due to the high density of the bales, which reduce the presence of the trigger factor such as oxygen, and to the plaster that works as a layer of protection $[16,17]$.

\subsection{The hygrothermal phenomena applied to straw}

Moisture is the greatest challenge affecting the structural integrity of a properly built straw bale house. Assuming that most of the direct sources of water can be avoided with an appropriate planning phase, the greatest danger comes from the level of the water vapour that can be found in the surroundings as well as stored.

Straw, like any hygroscopic material, can absorb and store vapour from the air until the equilibrium is reached, which equates vapour pressure of the surroundings. Monitoring the moisture content of hygroscopic materials

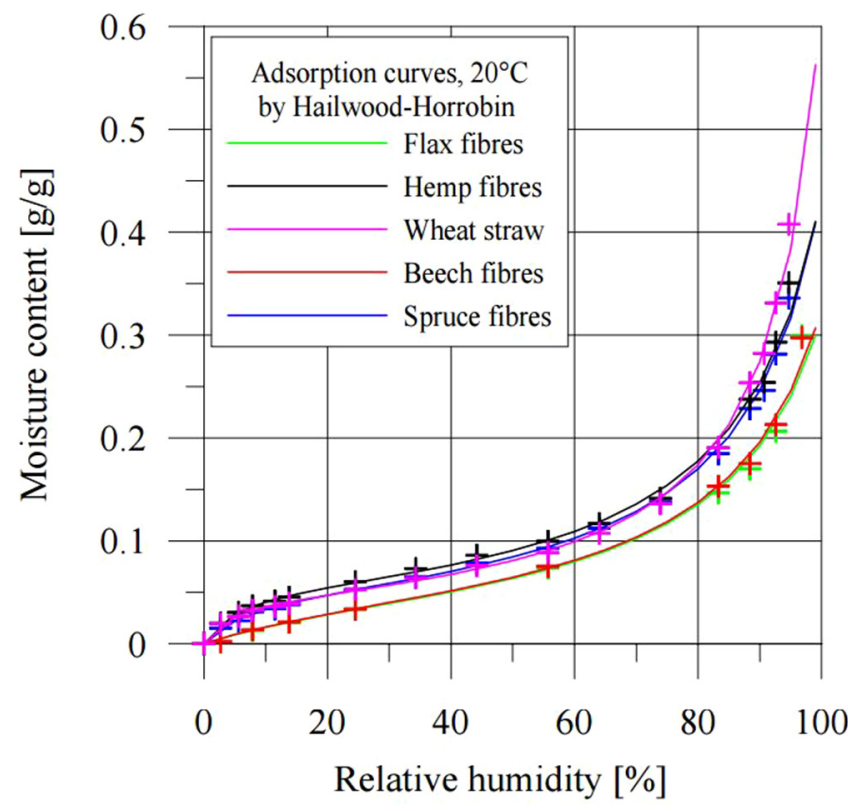

Fig. 1. Sorption isotherms of flax, hemp, wheat straw, beech and spruce fibres at $20^{\circ} \mathrm{C}$. Source: [24].

is fundamental to characterize them and prevent the reaching of critical levels, which may compromise performance and integrity. Storage capacity is described by a curve, unique for each material, called sorption isotherm. This curve relates to the moisture content with the relative humidity of the surroundings, and can be determined by following the current, UNI EN ISO 12571:2013 [18] standard.

Several experimental studies have led to the definition of the sorption isotherm of straw [19-24], which confirms its high storage capacity. Figure 1 shows sorption isotherms at $20^{\circ} \mathrm{C}$ for different pure fibres [24], in order to compare the hygroscopic behaviour of materials similar in terms of origin and construction. All these materials have indeed an organic nature and a comparable composition, and this reflects also in a similar storage capacity.

In confirmation of these assumptions, Figure 1 shows that all the sorption isotherms have similar trends, which differ only when the relative humidity reaches values higher than $90 \%$. Focusing on straw, at $95 \%$ of relative humidity, the moisture content increases significantly compared to other fibres. This might mean that other mechanisms are contributing, such as capillary condensation or water molecule cluster formation, and also that straw has a higher moisture storage capacity than other hygroscopic materials [24].

Straw is really susceptible to rotting, and its high storage capacity can lead to degradation that may compromise structural integrity and largely decrease longevity of buildings under certain conditions of relative humidity. Therefore, if straw overcomes the absorption limit, every molecule stored is available for microorganism. Hence, once fibres saturation, usually assessed at around $40 \%$ of dry basis moisture content, is reached it can easily be attacked by microorganism, which will lead to rot [2]. Dealing with phenomena that can increase the moisture 
Table 1. Summary of measured $R$ and $C$-values of plastered straw bale walls.

\begin{tabular}{|c|c|c|c|c|c|}
\hline Study & Procedure & $\begin{array}{l}\text { Wall } \\
\text { thickness [m] }\end{array}$ & $\begin{array}{l}\text { Orientation } \\
\text { of fibres }\end{array}$ & $\begin{array}{l}C \text {-value } \\
{\left[\mathrm{W} / \mathrm{m}^{2} \mathrm{~K}\right]}\end{array}$ & Comments \\
\hline Watts (1995) & Heat flow monitoring & 0.467 & Parallel & 0.2 & - \\
\hline Christian (1996) & $\begin{array}{l}\text { Guarded hot box, } \\
\text { full wall, to ASTM C } 236\end{array}$ & 0.47 & Parallel & 0.33 & $\begin{array}{l}\text { Deficiencies on the sample } \\
\text { have been noted. The test } \\
\text { was conducted again in } 1998\end{array}$ \\
\hline \multirow[t]{2}{*}{ Stone (1997) } & $\begin{array}{l}\text { Guarded hot box, } \\
\text { full wall, to ASTM C } 236\end{array}$ & $\mathrm{n} / \mathrm{a}$ & Perpendicular & 0.172 & $\begin{array}{l}\text { Not reliable results: the test } \\
\text { was stuffed with loose straw } \\
\text { to cover gaps and the was } \\
\text { performed before the plaster } \\
\text { completely dried off }\end{array}$ \\
\hline & & 0.584 & Parallel & 0.218 & \\
\hline Christian (1998) & $\begin{array}{l}\text { Guarded hot box, } \\
\text { full wall, to ASTM C } 236\end{array}$ & 0.483 & Parallel & 0.206 & - \\
\hline Wimmer (2000) & $\mathrm{n} / \mathrm{a}$ & 0.42 & $\mathrm{n} / \mathrm{a}$ & 0.12 & $\begin{array}{l}\text { Method and fibres } \\
\text { orientation in unknown }\end{array}$ \\
\hline \multirow[t]{2}{*}{ Andersen (2001) } & $\begin{array}{l}\text { Hot box, full wall, } \\
\text { to ISO } 8990\end{array}$ & 0.461 & Parallel & 0.203 & $\begin{array}{l}\text { Problems occurred during } \\
\text { the tests. Values cannot } \\
\text { be reliable }\end{array}$ \\
\hline & & 0.417 & Perpendicular & 0.196 & \\
\hline
\end{tabular}

Adapted from [1], [2] and [11].

content, such as rainfall, air leakage, ground moisture etc. is, therefore, one of the fundamental steps during the designing and the life-cycle phase of a straw envelope and, most of all, the controlling of the relative humidity level within the wall must have a decisive role, in order to defend the integrity of the building [1].

Given the importance of monitoring the water content within the straw, some tests have been conducted in order to define building hygrothermal behaviour and the influence that relative humidity may have on the conductance $C$ of a straw bale envelope. Experimental tests have led to a first characterization of straw but the goal of defining its hygrothermal behaviour is not, though, completely reached. Further studies are, indeed, needed to understand the performance of a material as complex as straw.

Table 1 shows the main assessment conducted on this topic since 1995, in order to define the conductance $C$ characterizing a straw bale wall. Laboratory tests studied a traditional stratigraphy made of a layer of straw plastered on the both sides and differ for thickness of the wall and orientation of the fibres.

As it can be seen, literature data focused on this topic shows several $C$-values, which do not converge on a common result, but they swing in a large range between 0.12 and $0.33 \mathrm{~W} / \mathrm{m}^{2} \mathrm{~K}$. Considering this it should be underlined that the tests were conducted according to different laboratory methods and that some tests were discarded due to inconveniences that occurred. Moreover, straw is an organic material and its performance is strongly variable depending on the characteristics of each stock. In the light of the above considerations, it is clear that the assessment of the $C$-value of the straw bale wall is a complex task to achieve and that a common value is difficult to establish, due to the unique characteristics of each bale.
Another essential value to characterize straw is the thermal conductivity. Some experimental tests have been conducted in the last few years regarding this topic. Unfortunately, all the tests presented above did not calculate the thermal conductivity of straw starting from the same sample, so a correlation between the $C$-value of the wall cannot be found. In Table 2 the main studies conducted from 1993 to 2014 are summarized.

The published results show high variations, which are reasonable for an organic material. Furthermore, it is permanently noticeable that the thermal conductivity is always higher with fibres parallel to the heat flux. The difference is balanced in construction by the greater thickness of the wall when laid with horizontal fibres [2]. The range of thermal conductivity values swing from $0.054 \mathrm{~W} / \mathrm{mK}$ to $0.068 \mathrm{~W} / \mathrm{mK}$ for horizontal fibres and from $0.045 \mathrm{~W} / \mathrm{mK}$ to $0.056 \mathrm{~W} / \mathrm{mK}$ for vertical fibres. These differences between tests results show the complexity inherent in any attempt to define an organic material like straw again.

\section{Laboratory tests}

\subsection{Sample}

The sample was assembled in different phases. Materials were positioned directly in the laboratory, in order to limit movement that could compromise the plaster's integrity. The specimen had to fit the dimensions of the climatic chamber exactly, so it measured $108.5 \mathrm{~cm} \times 40 \mathrm{~cm} \times 117 \mathrm{~cm}$. The stratigraphy was composed of a $38 \mathrm{~cm}$ thick layer of straw covered by three layers of hydraulic lime plaster on the outside surface and three layers of clay plaster on the inside surface. This stratigraphy reproduced a typical 
Table 2. Summary of straw thermal conductivities.

\begin{tabular}{|c|c|c|c|c|}
\hline Study & $\begin{array}{l}\text { Sample } \\
\text { thickness }[\mathrm{m}]\end{array}$ & $\begin{array}{l}\text { Density } \\
{\left[\mathrm{Kg} / \mathrm{m}^{3}\right]}\end{array}$ & $\begin{array}{l}\text { Orientation } \\
\text { of fibres }\end{array}$ & $\begin{array}{l}\text { Thermal conductivity } \\
\text { [W/ mK] }\end{array}$ \\
\hline \multirow[t]{2}{*}{ McCabe (1993) } & 0.127 & 133 & Parallel & 0.061 \\
\hline & 0.38 & 83 & Perpendicular & 0.046 \\
\hline Acton (1994) & 0.48 & 83 & Parallel & 0.054 \\
\hline Rissanen (1998) & $\mathrm{n} / \mathrm{a}$ & $35-97$ & Parallel & $0.039-0.057$ \\
\hline Christian (1998) & 0.38 & 81 & Parallel & 0.082 \\
\hline $\operatorname{GrAT}(2000)$ & $\mathrm{n} / \mathrm{a}$ & 100.8 & $\mathrm{n} / \mathrm{a}$ & 0.38 \\
\hline Wimmer (2000) & 0.3 & $\mathrm{n} / \mathrm{a}$ & $\mathrm{n} / \mathrm{a}$ & 0.045 \\
\hline \multirow[t]{2}{*}{ Andersen (2001) } & $\mathrm{n} / \mathrm{a}$ & 75 & Parallel & 0.057 \\
\hline & & 75 & Perpendicular & 0.052 \\
\hline \multirow[t]{2}{*}{ Andersen (2001) } & $\mathrm{n} / \mathrm{a}$ & 90 & Parallel & 0.06 \\
\hline & & 90 & Perpendicular & 0.056 \\
\hline \multirow[t]{3}{*}{ By og Byg (2001) } & 0.13 & 90 & Perpendicular & 0.056 \\
\hline & 0.15 & 90 & Parallel & 0.063 \\
\hline & 0.13 & 75 & Perpendicular & 0.051 \\
\hline \multirow[t]{2}{*}{ FIW (2003) } & 0.1 & 90 & Perpendicular & 0.056 \\
\hline & 0.1 & 90 & Assumed perpendicular & 0.045 \\
\hline Goodhev (2005) & $\mathrm{n} / \mathrm{a}$ & 60 & Parallel & 0.067 \\
\hline $\operatorname{DBU}(2008)$ & $\mathrm{n} / \mathrm{a}$ & 100 & $\mathrm{n} / \mathrm{a}$ & 0.045 \\
\hline Fasba (2014) & 1 & $\mathrm{n} / \mathrm{a}$ & $\mathrm{n} / \mathrm{a}$ & 0.052 \\
\hline
\end{tabular}

Adapted from [1], [2], [5], [6], [8-11].

external straw bale wall, which is currently used by Casalogica S.r.l., Italian leading company of straw bale building, which provided all the materials.

The sample was realized in a wooden frame representing the load bearing structure. The goal of the tests was to assess straw performances, so the frame was not under study but it was only used to facilitate handling and movement. The spacing between the laminated timbers was chosen in order to perfectly suit the climatic chamber dimension, nevertheless, it is comparable to the solution used in real houses. The frame was made with spruce GL24H laminated timber, which is typically used for the structure of real houses. The wood moisture content during the construction phase must be lower than $20 \%$, which is the limit fixed to avoid microbiological activity. The average dry basis moisture content at testing was $15 \%$, which is lower than the limit suggested by the standard, so not a cause of concern.

Straw bales provided for the sample were the two-string type of wheat straw bound with polypropylene strings. The three bales provided to assemble the laboratory sample had a measured density of $116 \mathrm{Kg} / \mathrm{m}^{3}$ and an overall thickness of $38 \mathrm{~cm}$. Two intact bales were used for the first and the second rows, positioned with horizontal fibres, so parallel to the heat flux. This can cause an increase of transmittance [7] but, on the other hand, enhances straw behaviour with vertical load [15]. The third row was made with three pieces of bale, $1 / 3$ of bale each, and loose straw to cover holes. Straw bale were piled in three rows, and then squeezed into the frame with a compression to reach the height of the timber frame. The assembly process is shown in Figure 2.
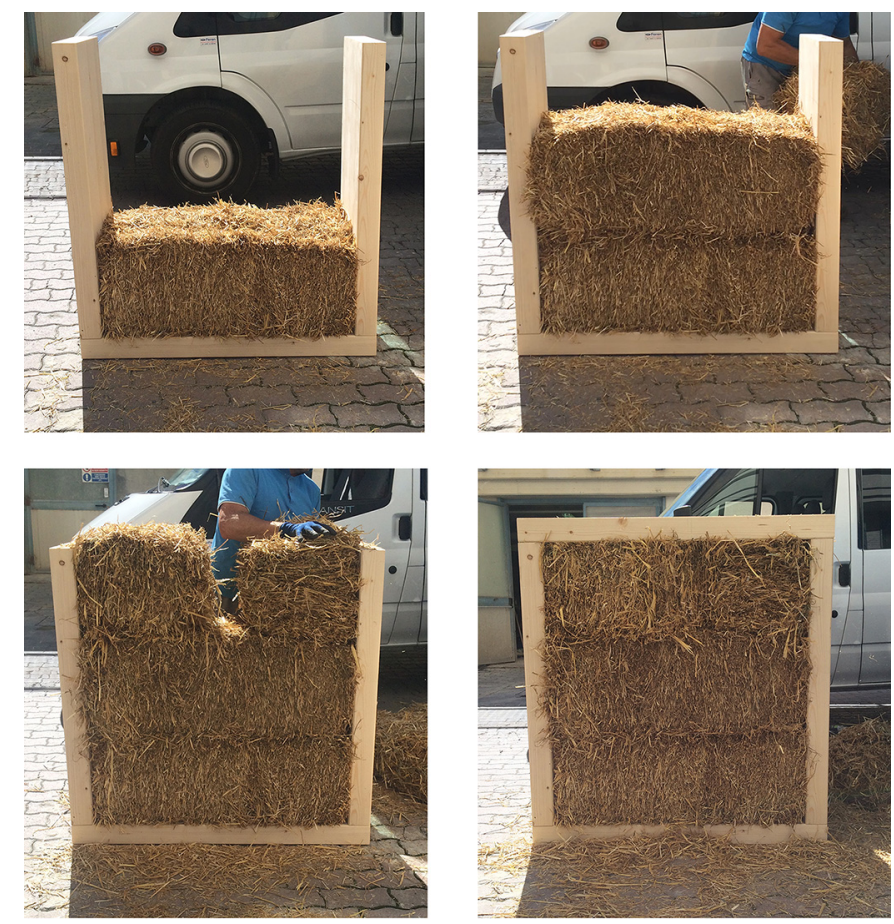

Fig. 2. Phases of the assembly of the laboratory sample.

Considering the organic nature of the straw, attention must be paid to the assessment of the initial water content of the material. Literature establishes $15 \%$ as the maximum limit of water content, beyond which the 
deterioration of the straw by decomposition can occur [20]. The measured average dry basis moisture content at testing was $9.2 \%$, lower than the worrying value.

The sample was then completed, covering the outdoor straw surface with three layers of hydraulic lime plaster, while for the indoor straw surface clay plaster was used. The straw bale wall, originally $38 \mathrm{~cm}$ thick, was then reduced to nearly $1 \mathrm{~cm}$ on each side, due to the plastering. The surface of a straw bale is typically rough and uneven, so the thickness of each layer could not be perfectly defined. A small part of the straw bale surface was impossible to consider as it was not only made of straw, but of a mix of straw and plaster, which is a composition with a higher thermal conductivity than only straw. Therefore, the calculations made from the collecting data considered the straw bale with a thickness of $36 \mathrm{~cm}$.

\subsection{Method}

The purpose of the assessment was to investigate the conductance $C$ of the straw bale wall at different steady boundary conditions. To achieve the goal six tests have been conducted following the method described in UNI ISO 9869-1 [25]. The climatic chamber was used to reproduce outdoor conditions, while indoor boundary conditions were reached involving different tools. Indoor temperatures were easily settled using the laboratory central heating at its maximum level. A warm mist humidifier connected to a humidity controller, which turned off the humidifier when the set value of $\mathrm{RH}$ was reached, provided indoor humidity, instead. In order to have a double check of the set boundary conditions, a thermo-hygrometer was placed inside the climatic chamber, while external condition was verified by a humidity sensor and thermocouple placed on the surface of the sample. Finally, since air infiltration could compromise the tests the sample's borders were sealed in order to avoid seepage from cracks and holes. The area around the specimen was also confined using a wooden structure and PVC. This allowed the maintenance of the steady-state conditions, defined for the laboratory set.

For the tests thermocouple were used to monitor surface temperatures, while a heat flux plate allowed to record the heat flux during the trials. Assessment of temperature and relative humidity trends within the wall was monitored by 4 sensors. Three probes were settled to define the behaviour of the plaster: one was placed between the straw and the first layer of hydraulic lime plaster, while, on the inside surfaces, a probe was positioned between the straw and clay plaster and another probe was settled between the first and the second layer of clay plaster. The high density of the bale made the settlement of the probe inside the straw difficult. The sensor, initially supposed to be settled with a depth of $19 \mathrm{~cm}$, was then positioned at $10 \mathrm{~cm}$ from the first layer of clay plaster as it is shown in Figure 3 . The awareness of the real position of the probes within the sample has led to a numerical model that truly represents the laboratory set.

During the tests, the outdoor and indoor conditions were simulated at constant values of temperature and relative humidity. The tests ran until equilibrium of temperatures was reached so the duration of each trial was

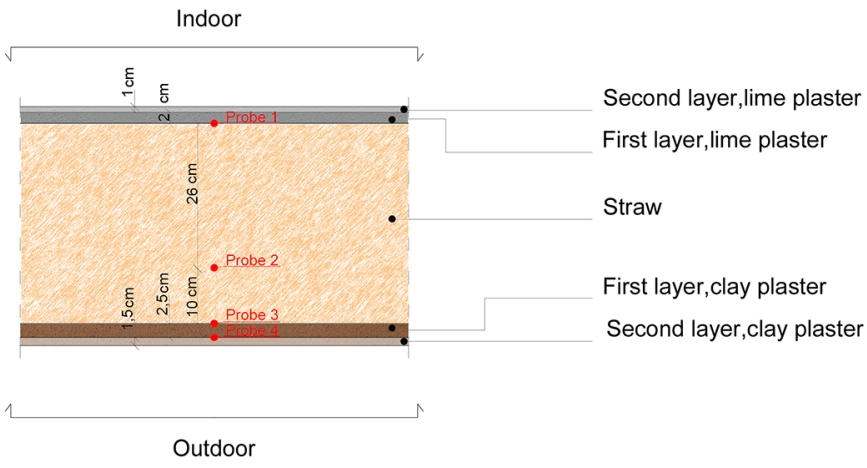

Fig. 3. Calculated probes position.

evaluated step by step, monitoring the trends of the results. From the experience gained it was found that usually it takes few days to reach a temperatures stable condition within the sample while other parameters, such as humidity, require longer tests to achieve the equilibrium.

The first laboratory investigation was conducted setting the same constant value of relative humidity for the indoor and outdoor environment. This first approach, with gradient temperature only, is a way of limiting variables influencing the transmittance results.

For all the following tests the level of relative humidity has gradually been increased. This allowed the calculation of transmittance with different boundary conditions and to then calculate the influence of the surroundings on it.

\subsection{Results and further works}

The test was conducted under steady-state conditions summarized in Table 3. Since the laboratory set was highly convoluted, it was complex to always maintain constant boundary conditions under control. Therefore, some tests were stopped before the expected time. The values obtained from these trials were not then taken into account during the reworking phase, but they were used as a good double check of the work, since they confirmed the results derived from longer tests.

As we predicted, collected data shows that temperature equilibrium was quickly achieved in a period of 2-3 days, while the relative humidity equilibrium was barely reached, probably due to the high thermal and moisture storage capacity of straw. Using these laboratory tests as a starting point, it can be asserted that the necessary running period for further trials, which have the purpose to achieve relative humidity equilibrium, should last at least ten days.

The monitored data from thermocouples and the heat flux plates on the surfaces allowed the calculation of the conductance $C$ of the sample of the straw bale wall, according to the formula suggested in UNI 10355 [26]. The goal of the tests was to establish a $C$-value common for each case study. The $C$-values were calculated with the progressive average method, and their trends were then compared, as it is shown in Figure 4.

The graph with the summary of conductance values shows a trend to reach an asymptote at $0.12 \mathrm{~W} / \mathrm{m}^{2} \mathrm{~K}$. 
Table 3. Summary of timing and boundary conditions of each laboratory tests.

\begin{tabular}{lllllll}
\hline & \multicolumn{2}{c}{ Environment set values } & & \multicolumn{2}{c}{ Climatic chamber set values } & Hours \\
\cline { 2 - 3 } & Temperature $\left[{ }^{\circ} \mathrm{C}\right]$ & Relative humidity $[\%]$ & & Temperature $\left[{ }^{\circ} \mathrm{C}\right]$ & Relative humidity $[\%]$ & {$[\mathrm{h}]$} \\
\hline Case I & 26 & 50 & 5 & 50 & 95 \\
Case II & 27 & 60 & 5 & 50 & 142 \\
Case III & 27.5 & 50 & 55 & 50 & 194 \\
Case IV & 25 & 50 & 10 & 30 & 93 \\
Case V & 26 & 50 & 10 & 30 & 358 \\
Case VI & 26.5 & 65 & 0 & & 30 & 378 \\
\hline
\end{tabular}

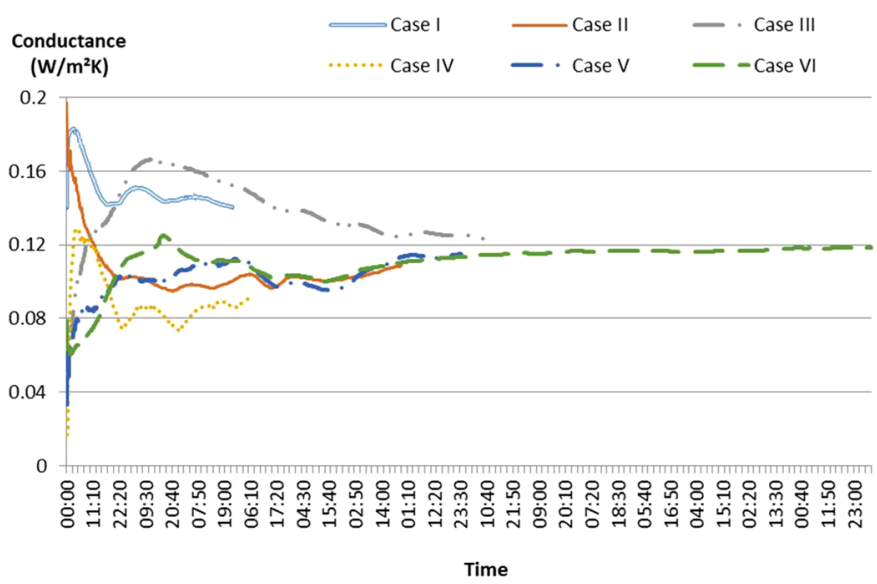

Fig. 4. Trends of the conductance values calculated from laboratory tests.

The values of the tests with a shorter duration show an intention of the curves to reach the asymptote just mentioned, but the trial was too brief to give reliable results. Hence, to calculate the sample resistance value, only tests with a longer duration have been taken into account and the conductance value of the sample found is settled at $0.12 \mathrm{~W} / \mathrm{m}^{2} \mathrm{~K}$. Starting from the $C$-value the resistance of the straw bale wall sample under investigation has been deducted, with a value of $8.33 \mathrm{~m}^{2} \mathrm{~K} / \mathrm{W}$. Resistance value was calculated according to UNI EN ISO 6946 [27], which is specific for non-homogeneous materials.

The calculation of the resistance value of the sample has been useful in order to investigate the thermal conductivity of straw, at least approximately, considering the complexity of the material due to its organic nature. Straw is a nonhomogenous material, so thermal conductivity should have been calculated, in accordance with UNI EN ISO 10456 [28], using conversion factors to calculate the design value $\left(\lambda_{\mathrm{d}}\right)$. Available standards show lack of information in terms of characterization of straw as building material, so appropriate conversion factors cannot be found. Evaluated thermal conductivity has been, then, calculated according to UNI EN ISO 6946 [27], which is typical for a homogeneous material. The purpose of this study was to create a numerical model, based on measured data. Software WUFI, chosen to run simulations, allows inserting the evaluated thermal conductivity value to characterize a material and the design thermal conductivity value can be added only to better define the material properties. The other objective was to compare the measured results with literature data, which refers, as well, to evaluated thermal conductivities. Therefore, for the aim of these laboratory tests and for this lack of information concerning straw material, only the evaluated thermal conductivity has been taken into account. The estimated thermal conductivity has shown a range of values from $0.044 \mathrm{~W} / \mathrm{mK}$ to $0.046 \mathrm{~W} / \mathrm{mK}$. A comparison with literature data of thermal conductivity indicates different measurements: values resulting from previous laboratory tests on samples with horizontal fibres swing between 0.054 and $0.068 \mathrm{~W} / \mathrm{mK}$ and in a range between 0.045 and $0.052 \mathrm{~W} / \mathrm{mK}$ for perpendicular fibres.

Since literature data are too diverse to choose a determined value and also since some authors have assessed values near to the one presented in this paper, laboratory tests results are taken into account in order to characterize straw material used in the numerical analyses.

Even if it was not the purpose of the experimental tests, the rework of results allowed making a first correlation between thermal conductivity values and relative humidity. The calculated results confirmed what could be deducted from theory: the increase of the relative humidity within the material lead to higher values of thermal conductivity, as it is shown in Figure 5.

\section{Numerical analyses}

\subsection{Sample}

In order to compare laboratory results with numerical model software WUFI Pro 6.0 [29], supplied by Fraunhofer IBP, has been used. This software provides a dynamical simulation that better suit the hygrothermal wall behaviour, compared with a steady-state calculation. Even if laboratory tests were conducted setting steady-state boundary conditions characterized by constant values, hygroscopic properties of materials are better described with a dynamic software instead of a steady state one. Beside basic data, such as density or porosity, WUFI allows characterizing materials in detail describing hygrothermal 


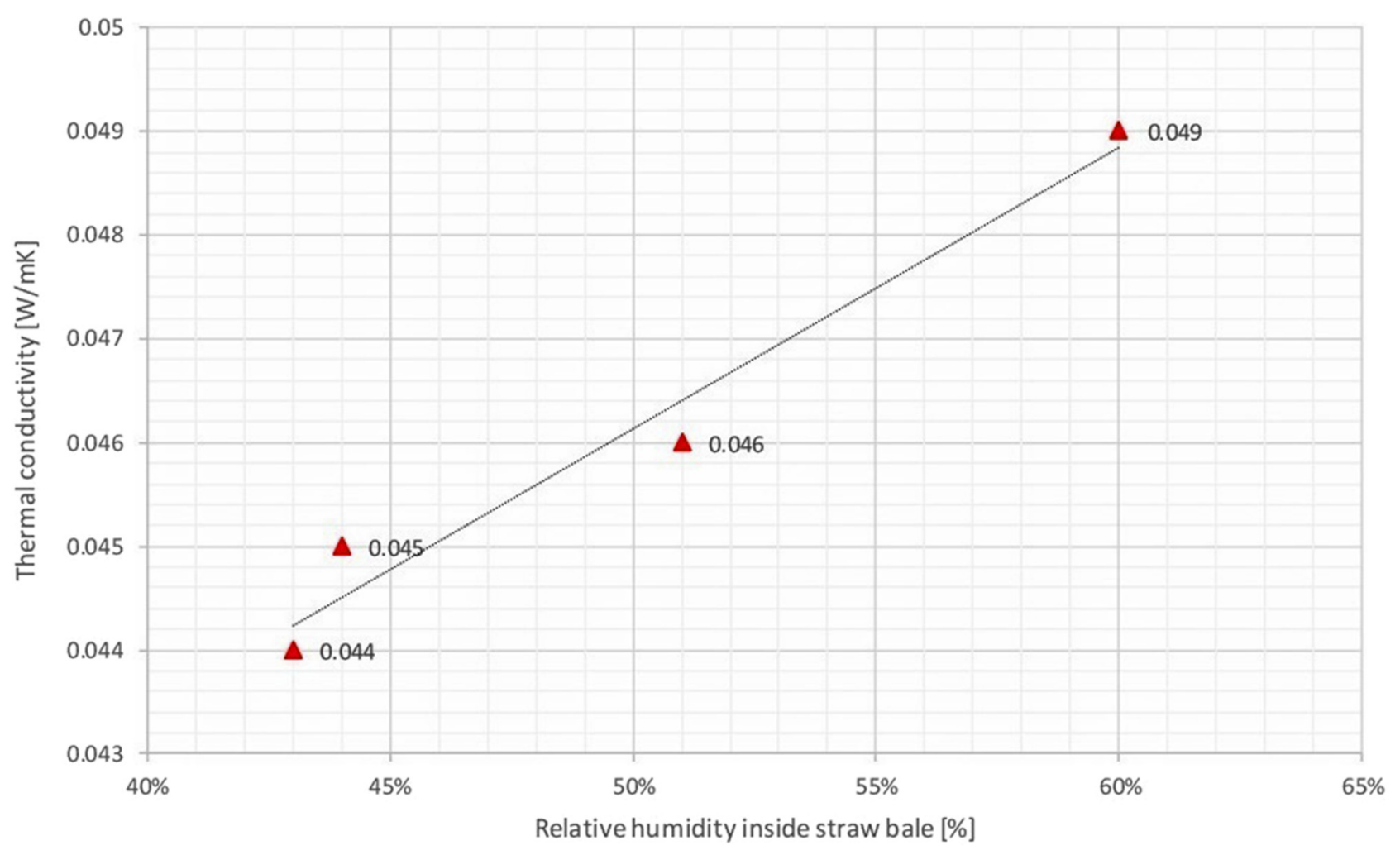

Fig. 5. Correlation between thermal conductivity value and relative humidity.

parameters with temperature or humidity-dependent function. These reasons have led to the choice of using dynamic simulation software and force it to represent a steady-state condition used in the lab.

The numerical model was created according to the data collected during laboratory tests. Figure 6 shows the stratigraphy of the sample reproduced with the WUFI. The monitoring positions for the software have been placed considering the probe position in the real sample. The monitor position with WUFI allows the knowledge of the simulated values of temperature, relative humidity, moisture content and mould risk in that specific point.

Materials were chosen in order to reproduce a numerical model, which was as close as possible to the real sample. Straw was characterized using the collected laboratory data in order to faithfully reproduce the sample. Thermal conductivity deducted from laboratory data has shown slightly different values, for this reason each numerical analysis has then been run using the appropriate lambda, in order to better replicate the sample results. All the additional parameters required by the software, such as porosity, vapour resistance and hygrothermal functions, were set, instead, according to reliable literature data and from the WUFI database.

Lime and clay plaster were complex to define, since they had been created and applied directly to the sample. The characteristics of the plasters in use for the sample, were then too generic to be used, therefore, data has been taken from literature and the WUFI's database. Materials were

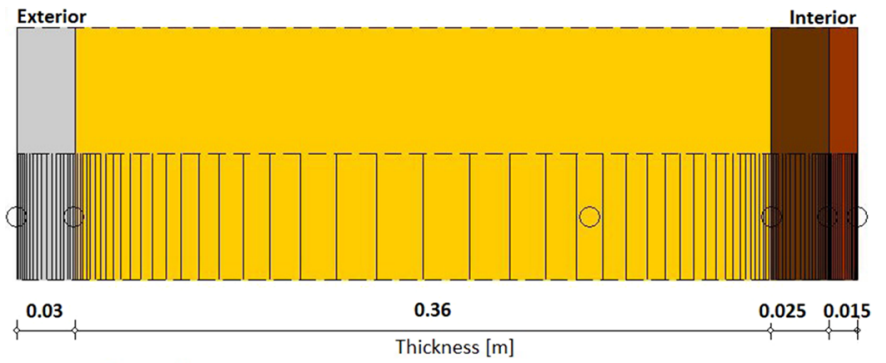

Monitor positions

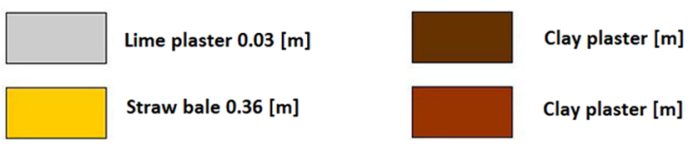

Fig. 6. Wall assembly and monitor positions.

chosen from the list provided by Fraunhofer IBP, while the thermal conductivity and the water vapour diffusion resistance factor have been picked from FASBA [8] for both plasters.

Table 4 collects all the parameters set for the numerical model.

\subsection{Method}

WUFI provides a dynamic simulation that perfectly suits the hygrothermal behaviour of materials but at the same time does not represent laboratory conditions. Therefore, 
Table 4. Material properties required for WUFI simulations.

\begin{tabular}{llllllll}
\hline Material & $\begin{array}{l}\text { Layer } \\
\text { thickness } \\
{[\mathrm{m}]}\end{array}$ & $\begin{array}{l}\text { Bulk density } \\
{\left[\mathrm{kg} / \mathrm{m}^{3}\right]}\end{array}$ & $\begin{array}{l}\text { Porosity } \\
{\left[\mathrm{m}^{3} / \mathrm{m}^{3}\right]}\end{array}$ & $\begin{array}{l}\text { Sp. heat capacity } \\
(\text { dry material) } \\
{[\mathrm{J} / \mathrm{kg} \mathrm{K}]}\end{array}$ & $\lambda[\mathrm{W} / \mathrm{mK}]$ & $\mu[-]$ & $\begin{array}{l}\text { Typical built- } \\
\text { in moisture } \\
{\left[\%^{*}\right]}\end{array}$ \\
\hline Clay plaster & $0.040^{*}$ & $1514^{* *}$ & $0.4^{* *}$ & $850^{* *}$ & $0.7^{* *}$ & $10^{* *}$ & - \\
Straw & $0.36^{*}$ & $116^{*}$ & $0.9^{* *}$ & $2000^{* *}$ & $0.44-0.045-0.046^{*}$ & $2^{* *}$ & $10.65^{* *}$ \\
Lime plaster & $0.03^{*}$ & $160^{* *}$ & $0.3^{* *}$ & $850^{* *}$ & $0.8^{* *}$ & $15^{* *}$ & - \\
\hline
\end{tabular}

${ }^{*}$ Lab result, ${ }^{* *}$ Literature data.
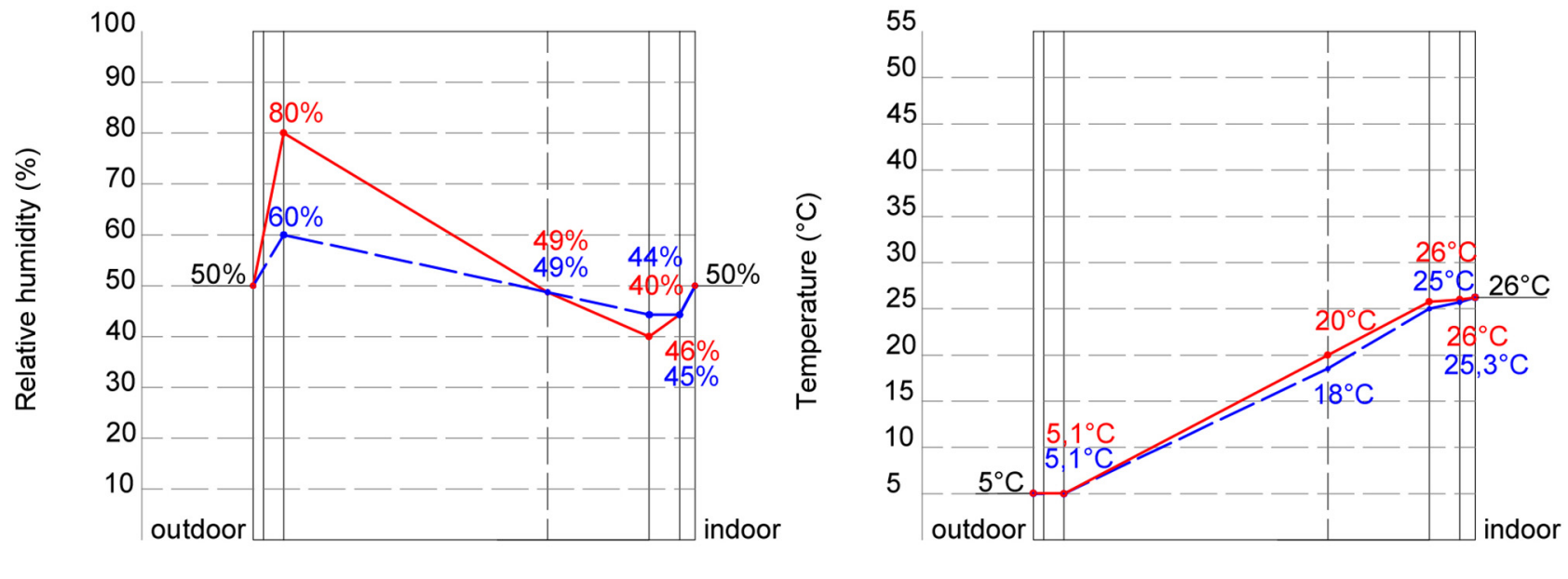

Fig. 7. Comparison between WUFI and laboratory results. Duration of the laboratory trial $94 \mathrm{~h}$.

some parameters provided by the software have been simplified or totally omitted in order to reproduce a calculation under steady-state conditions. Laboratory sets were modelled using the sine curves method, both for exterior and interior climate conditions by setting a constant value for temperature and relative humidity, equal to those maintained by the climatic chamber. Other additional variables provided by the software, such as orientation, wind speed etc., were then omitted to better fit the laboratory set.

At last, in order to achieve steady-state equilibrium within the wall assembly, simulations with a 5 years running period have been conducted. The WUFI allows dynamically calculating heat transport and moisture transport. The time step was set at $1 \mathrm{~h}$, in order to monitor temperatures and humidity trends inside the wall and make a trustworthy comparison with the real sample.

\subsection{Results and further works}

The comparison between laboratory values and dynamic simulations has shown similar results. Temperatures measured by probes usually achieve closer values to those provided by the software. This is clearly related to the facility of the sample of reaching equilibrium in terms of temperatures, even if the trials had a short duration. The comparison between the real sample and the numerical model has lead then to a reliable match.

The assessment of relative humidity is, instead, more complex to analyse. Laboratory tests have shown the sample's difficulties in reaching an equilibrium in terms of relative humidity. Humidity assessment needs, indeed, longer duration of the tests, and that is clear in the cases of study characterized by a short duration (94 h), which have shown a trend of humidity far from equilibrium. This assertion is confirmed by the comparison with the numerical model behaviour, which shows significant variations between the trends of relative humidity, as can be noticed in Figure 7 .

Analyses provided by the software simulate the sample behaviour for a 5-years period, which is clearly enough for the wall assembly to reach equilibrium, while laboratory tests lasted only for a few weeks, sometimes a few days. The reason for these differences should be then investigated according to the duration of each case, since the gap between the laboratory and WUFI's results deeply decreases with the increasing of the assessment duration. Considering this assumption, only the longer trial has been investigated, which gave more reliable results, reaching equilibrium for both temperature and relative humidity. The comparison between the last trials and the numerical model has shown a good correlation between laboratory 


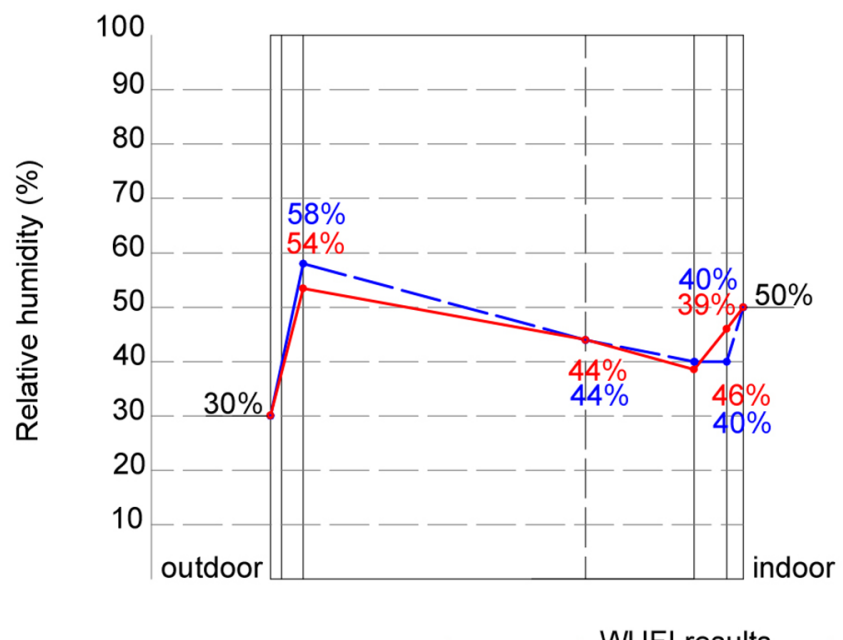

WUFI results

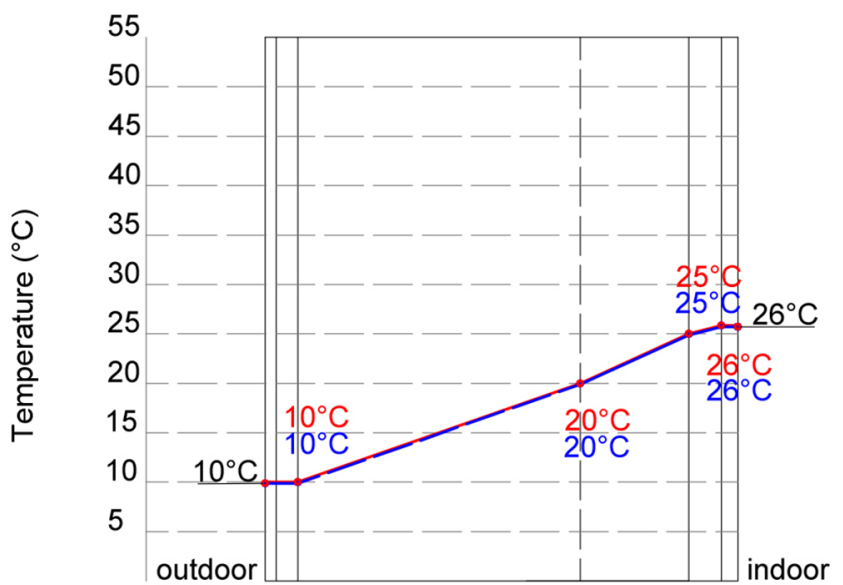

Laboratory results

Fig. 8. Comparison between WUFI and laboratory results. Duration of the laboratory trial $178 \mathrm{~h}$.

assessments and dynamic simulations, as it can clearly be seen from Figure 8.

The simulations ran with WUFI and the values measured by probes show a similar trend, not only for temperatures, but also for relative humidity. The variations are, indeed, slight and they can be considered negligible.

\section{Discussion}

The laboratory tests herein presented have shown that it is quite complicated to measure the hygrothermal values of natural and non homogenous materials such as straw bale. Nevertheless, the laboratory setting reproducing steady conditions (with different boundary conditions and duration) has provided quite good results, aligned with the lowest presented in literature. These first tests demonstrated that testing time is a determining factor for ensuring reliable results. In the perspective of further researches, test's duration must take into account both straw high thermal capacity and straw high moisture storage capacity. Further tests must have, therefore, a longer duration (15 days or more) in order to achieve equilibrium both in terms of temperature and relative humidity. Furthermore, a semisteady or dynamic boundary conditions should be adopted as in the outdoor test cells, which have recently renovated at the University of Brescia (Building Envelope ouTdoor Thermal Testing facility - BEsT ${ }^{3}$ facility) [30]. This facility allows assessing building components with controlled interior environment and maintaining real climate data for the outside boundary conditions.

If the experimental tests have already been carried out in the studies above mentioned, the numerical analyses can be considered the innovative contribution of this study. Once the hygrothermal properties of the straw bale are properly defined using laboratory tests, numerical model can be used in the designing phase to predict the building envelope behaviour. With reference to the present study, the numerical analyses have only partially used the potential of the software, in order to reproduce the laboratory set. An interesting development would be to investigate a comparison between a sample in real conditions and a numerical model under dynamic conditions. In this perspective BEsT ${ }^{3}$ facility will allow to obtain more reliable values to be used as inputs for WUFI software by taking into account the simulations and also the dynamic thermal properties provided by the software, which can be critical for an organic material as straw, and also to deal with the assessment of summer period performances of this kind of walls.

\section{Conclusions}

In order to avoid critical situations that can compromise performance and integrity of buildings, moisture content within a straw bale wall must be monitored. The tests carried out to define the hygrothermal behaviour of straw have led to a value of conductance of $\left(0.12 \mathrm{~W} / \mathrm{m}^{2} \mathrm{~K}\right)$, resistance of $\left(8.33 \mathrm{~m}^{2} \mathrm{~K} / \mathrm{W}\right)$ and thermal conductivity of $(0.044-0.046 \mathrm{~W} / \mathrm{mK})$. In comparison with other research related to $\lambda$ assessment, the results of the present tests are positioned among the lowest literature data values. Since also literature data does not converge on a common result, but swings in a range of values, and since the measured results shown in this paper are in line with some experimental tests conducted on this topic, the obtained laboratory results have been used as a starting point to create a numerical model, which faithfully reproduced the real sample.

\section{Conflict of interests}

The authors declared no potential conflicts of interest with respect to the research, authorship, and/or publication of this article.

Authors of this research work express sincere appreciation to University of Brescia, Casalogica s.r.l. Energethica and Micheletti Ingegneria s.r.l. for giving full support and laboratory equipment to run these experimental tests. 


\section{References}

1. N.R. Bronsema, Moisture movement and mould management in straw bale walls for a cold climate. Thesis, University of Waterloo, Ontario, Canada, 2010

2. J.M.J. Carfrae, The moisture performance of straw bale constructions in a temperate maritime climate. $\mathrm{PhD}$ thesis, University of Plymouth, Plymouth, UK, 2011

3. B. King, Design of straw bale buildings - The state of the art, Green building press, San Rafael, CA, USA, 2007

4. G. Minke, F. Mahlke, Building with straw: Design and technology of a sustainable architecture, Princeton Architectural Press, New York, 2005

5. Teknologisk Institut. Prøvningsrapport nr. 00163/00180/ 01001/01002/01003/01030/01041. DANAK, Denmark, June 2001

6. DBU. Grundlagen zur bauaufsichtlichen Anerkennung der Strohballenbauwiese- Weiterentwicklung der lasttragenden Konstruktionsart und Optimierung der bauphysikalischen Performance, 2008. Available at https://www.dbu.de/pro jekt 22430/01 db 2409.html (accessed 28-11-2018)

7. O. Douzane, G. Promis, J.M. Roucoult, A.D. Tran Le, T. Langlet, Hygrothermal performance of a straw bale building: in situ and laboratory investigations, J. Build. Eng. 8, 91-98 (2016)

8. Fasba. Strohbaurichtlinie. Available at http://fasba.de/wpcontent/uploads/2016/05/SBR-2014-11-22-end.pdf, 2014 (accessed 28-11-2018)

9. FIW München. Wärmeleitfähigkeit nach DIN 52612. Prüfbericht nr. F. 2-430/03, FIW München, 2 May 2003

10. GrAT. Untersuchungsbericht über die Messung der Wärmeleitfähigkeit von Strohballen. Report nr. MA 39-VFA 20000563.02, Magistrat der stadt Wien, AUS, 6 November 2000

11. R. Wimmer, H. Hohensiinner, L. Janisch, M. Drack, Heat insulation performance of straw bales and straw bale walls, 2000. Available at www.naturalbuildingcoalition.ca/Resour ces/Documents/Technical/heat_insulation_performance strawbales.pdf (accessed 03-12-2018)

12. F. D'Alessandro, F. Bianchi, G. Baldinelli, A. Rotili, S. Schiavoni, Straw bale constructions: Laboratory, in field and numerical assessment of energy and environmental performance, J. Build. Eng. 11, 56-68 (2017)

13. R. Dalmeijer, Straw bale sound insulation and acoustics. Last Straw: Int. J. Straw Bale Natural Build. 53, 8-9 (2006)

14. S. Dance, P. Herwin, Straw bale sound insulation: Blowing away the chaff, in: Proceedings of Meetings on Acoustics, ICA 2013, Montreal, Canada, 2-7 June 2013, vol. 19, 015011
15. A. Taha, G. Heiko, W. Wei, Performance of straw bale wall: a case of study. Energy Build. 43, 1960-1967 (2011)

16. D. Peroni, Analisi LCA delle case di paglia di Pescomaggiore (AQ). Thesis, University of Bologna, Italy, 2010

17. B. Theis, Straw bale fire safety, 2003. Available at https:// tallerconco.org/wp-content/uploads/2017/05/Fire_safety. pdf (accessed 03 December 2018)

18. UNI EN ISO 12571:2013. Hygrothermal performance of building materials and products - Determination of hygroscopic sorption properties

19. C.P. Hedlin, Sorption isotherms for five types of grain straw at $70^{\circ} \mathrm{F}$, Can. Agric. Eng. 9, 37-42 (1967)

20. M. Lawrence, A. Health, P. Walker, Determining moisture levels in straw bale construction, Constr. Build. Mater. 23, $2763-2768$ (2009)

21. M. Lawrence, A. Heath, P. Walker, Monitoring of the moisture content of straw bale walls, in: Sustainability in Energy and Buildings: Proceedings of the International Conference in Sustainability in Energy and Buildings (SEB'09), Brighton, UK, April, 29-30 and May 1, 2009, vol. Part 3, pp. 155-164

22. P. Sain, F.E. Broadbent, Moisture adsorption, mold growth, and decomposition of rice straw at different relative humidities, Agron. J. 67, 759-762 (1975)

23. A.R. Staniforth, Moisture content of straw. Cereal straw, Oxford University Press, Oxford, 1979, pp. 36-38

24. K. Strømdahl, Water sorption in wood and plant fibres. $\mathrm{PhD}$ thesis, Technical University of Denmark (DTU), Denmark, 2000

25. UNI ISO 9869-1:2015. Thermal insulation - Building elements - In situ measurement of thermal resistance and thermal transmittance - Part 1: Heat flow meter method

26. UNI 10355:1994. Murature e solai. Valori della resistenza termica e metodo di calcolo

27. UNI EN ISO 6946:2008. Building components and building elements - Thermal resistance and thermal transmittance Calculation method

28. UNI EN ISO 10456: 2008. Building materials and products Hygrothermal properties - Tabulated design values and procedures for determining declared and design thermal values

29. WUFI. Website, www.wufi.it (accessed 3-12-2018)

30. A. Mesa, A. Arenghi, M. Pasetti, A testing facility for the thermal characterization of building envelopes in outdoor operating conditions, XX International Scientific Conference Energy Management of Municipal Facilities and Sustainable Energy Technologies EMMFT 2018, 10-13 December, Russia, in press

Cite this article as: A. Mesa and A. Arenghi: Hygrothermal behaviour of straw bale walls: experimental tests and numerical analyses. Sust. Build. 4, 3 (2019). 